\title{
Confronting an augmented reality
}

\author{
Danny Munnerley ${ }^{\mathrm{a}, \mathrm{b} *}$, Matt Bacon ${ }^{\mathrm{b}}$, Anna Wilson ${ }^{\mathrm{b}, \mathrm{d}}$, James Steele ${ }^{\mathrm{a}}$, \\ John Hedberg ${ }^{\mathrm{c}}$ and Robert Fitzgerald ${ }^{\mathrm{a}}$
}
${ }^{a}$ INSPIRE Centre, University of Canberra, Canberra, ACT Australia; ${ }^{b}$ Teaching and Learning Centre, University of Canberra, Canberra, Australia; ' $S$ chool of Education, Macquarie University, Sydney, Australia; ${ }^{d}$ Physics Education Centre, Australian National University, Canberra, Australia

(Received 11 March 2012; final rersion received 31 May 2012)

\begin{abstract}
How can educators make use of augmented reality technologies and practices to enhance learning and why would we want to embrace such technologies anyway? How can an augmented reality help a learner confront, interpret and ultimately comprehend reality itself? In this article, we seek to initiate a discussion that focuses on these questions, and suggest that they be used as drivers for research into effective educational applications of augmented reality. We discuss how multi-modal, sensorial augmentation of reality links to existing theories of education and learning, focusing on ideas of cognitive dissonance and the confrontation of new realities implied by exposure to new and varied perspectives. We also discuss connections with broader debates brought on by the social and cultural changes wrought by the increased digitalisation of our lives, especially the concept of the extended mind. Rather than offer a prescription for augmentation, our intention is to throw open debate and to provoke deep thinking about what interacting with and creating an augmented reality might mean for both teacher and learner.
\end{abstract}

Keywords: augmented reality; immersive learning; cognitive dissonance; variation theory; constructionism; international; moving learners; pioneering uses; enthusing learners; mainstreaming

\section{Introduction}

As a relatively new and rapidly developing technology, applications for mobile devices and web cameras that augment reality with digital objects are being taken up as potential educational tools by the usual vanguard of technophiles and early adopters. In the rush to adopt new technologies, there has been limited consideration of how augmenting reality might enhance the process of learning itself - that is, little consideration of why we might want to embrace such technologies more broadly, beyond the opportunities for mobility and flexibility. In the literature, there is little empirical work when compared with the volume of narrative studies (Dünser, Grasset, and Billinghurst 2008). However, the traditional response to develop experimental designs where augmented reality (AR) is tested against other educational approaches also presents challenges when analysing the impact of technology on educational outcomes (see Ross, Morrison, and Lowther 2010, p. 19). In this gap,

*Corresponding author. Email: danny.munnerley@canberra.edu.au 


\section{Munnerley et al.}

there is a danger of educational applications being driven by what is technically possible, and by the interests and agendas of the early adopters, rather than what is pedagogically desirable, or empirically defensible. The risk of such a fragmented approach to AR implementation may be to make it harder for academics and teachers to incorporate augmentation into their learning and teaching practices, and it may even alienate the less technically minded, with AR left seeming as yet another flash-in-the-pan, short-lived technological toy, accessible only to those with technical know-how and high levels of IT literacy and competence.

In this article, we discuss how the idea of augmenting reality with varied perspectives links to existing theories of education and learning. In particular, we focus on ideas of cognitive dissonance and variation, although it is important to note connections with constructivist approaches, activity theory and the concept of visual learning. We argue that AR offers an inherently student-centred approach to the design of curricula and learning activities. AR technologies enable learning to be immediately linked to a database of reference materials and not to require rigidly structured learning sequences, followed in the same order at the same time by all students. Such flexibility should help facilitate transfer of learning into new contexts with little additional requirement for constructed learning activities. We also discuss connections with broader debates brought on by the social and cultural changes wrought by the increased digitalisation of our lives, especially the concept of the extended mind inherent in networked learning approaches.

We start by defining what we mean by AR, with the intention of freeing it from specific technologies and hence opening it up for integration in a broader philosophy of education. We stress that augmented realities, unlike virtual realities, are not substitutions for physical reality; not approximations to reality; but the layering of perspectives and experiences to augment and enrich reality. We then discuss what opportunities AR opens up, and how those opportunities might be exploited within a given (constructivist) approach to learning and teaching. Finally, we consider existing applications of AR, trends in AR research and possibilities for uses of this technology in education.

\section{What is AR?}

We embrace a broad definition of AR, using the term to describe real-time views of a physical, real-world environment whose elements have been augmented, enhanced, enriched or diminished by computer-generated sensory input, such as sound or graphics as a layer or projection.

Early uses of AR focused on the use of web cameras to display rendered 3D graphics when a particular object or image marker was viewed through them. Even now, this conception of AR pervades much of the literature. In their recent analysis of the success of the Horizon Reports' forecasts concerning the uptake and impact of new technologies on education, Martin et al. describe AR as "basically merg[ing] information or images with video streamed from a webcam" (Martin et al. 2011). They acknowledge that this goes "a step beyond data mashup" (Martin et al. 2011) but offer no explanation of how or why it might be an improvement. In this view, $\mathrm{AR}$ is distinct from virtual reality mainly in that it "uses real-world images in real time" (Martin et al. 2011). Another recent article, describing an application of AR in an educational context, defines it as "the technology of adding virtual objects to real scenes through enabling the addition of missing information in real life" (El Sayed, 
Zayed, and Sharawy 2011). As with the previous definition, the focus here is on providing additional information, in this case of a type that might be missing or inaccessible to students in the physical world, such as anatomy education where it requires a fair amount of effort, expertise and expense to teach (Blum et al. 2012).

Outside the educational context, the term has grown to include any actions that augment or expand the physical environment, whether viewed through mobile devices or projected onto real surfaces. There is no need for such augmentation to be limited to the provision of visual information; there are rich opportunities to provide access to alternative visions and vistas and to alternative imaginations with a wide variety of sensory inputs. There is also a wide scope for providing more engaging and interactive experiences through live feedback of visual analytics/ simulation data or parametric/generative modelling.

Augmented reality may also be defined as the product of any activity that creates new dimensions to the physical spaces we usually inhabit. Technologies for augmenting reality allow us to insert virtual objects in real spaces, openly accessible to anyone with access to what is now mainstream hardware. With a web-enabled phone or tablet, hidden layers, suspended in the virtual dimensions within real space, become visible. The fact that these new layers can be accessed with consumer-level mobile devices means that they offer a uniquely open way to enrich environments and offer multiple, flexible learning opportunities.

Augmented reality offers opportunities to expand the boundaries of formal learning spaces to create new dimensions in mobile learning and to increase connectedness of learners in multiple contexts. From simple systems where a tagged artefact reveals hidden images when viewed through a fixed web camera to interactive environments accessible from mobile devices allowing for communication and codesign. AR is already being embraced across many disciplines (Lee 2012). There is a real imperative for the education discipline to explore ways of using AR to enhance student learning and develop a deep understanding of the augmented learning processes.

\section{Recognising and confronting a changed reality}

Our conception of what AR means, and what it can offer to learning and teaching, is rooted in a broader context of change: changes to the world we inhabit and to the ways in which we interact with it.

One obvious way in which our world has changed is the changed status of information and knowledge. Over the last two decades, we have seen a vast increase in the volume and accessibility of information available to society. From a world in which specialist knowledge was precisely that - the domain and property of the specialist, out of the reach of the majority of the population - and where possession of such information conferred value on the possessor, we have entered a world where more academic, technical, literary, personal and scientific knowledge is available through websites than ever before. Ownership and location of knowledge has become blurred, spread over a distributed network that is increasingly independent of the individuals responsible for initial knowledge creation and information upload. In this sense, knowledge and knowledge production processes are increasingly being democratised.

It is not just the availability of information that has changed, but also the ways we access and interact with it. What would previously have constituted cognitive processes that we might unquestioningly locate in the brain are being increasingly 


\section{Munnerley et al.}

extended via our embrace of the digital environment. We expect to be able to find the answer to any question, immediately, at the touch of a finger on a screen. We use our mobile devices to save us memorising information such as phone numbers. We store and retrieve memories of music and TV on YouTube; we store, retrieve and share more personal memories on sites such as Facebook and Flickr. The idea of an extended or networked human mind, which incorporates interactions with elements of the environment, and is not restricted to the boundaries of flesh and bone, was first introduced by Clark and Chalmers almost 15 years ago (Clark and Chalmers 1998); its relevance has only increased since then, as more and more of our intellectual functions are outsourced to computers and computer networks.

Learning processes themselves may change in response to such a changed environment. Our cognitive processes, indeed our very perceptual apparatus, may need to be reconceptualised as we adapt ourselves to the new tools now available. We are swimming in a sea of facts, opinions and assertions, buffeted by eddies of chatter and communication. Until now, our interactions with these data have been simple extensions of our historical approach, developed in an era when we had only limited data to interact with: we conduct a targeted search, on narrow, defined terms, looking for knowledge objects that conform to pre-existing expectations or specifications. We know what we are looking for, and search until we find it, excluding those results that do not fit the bill. But is this the right way for us to interact with our increasingly rich knowledge environment?

We may draw a comparison with the methods of scientific research. Our traditional, Popperian conception of research is that the scientist forms a hypothesis, then designs and performs a specific experiment to test it. The experiment is designed to control for variables that might confound the analysis; the scientist carefully records the relevant data. Irrelevant data (the humming of electronic modules, the sound of cooling fans, the smell of singed dust) are not recorded. But is this what really happens? Increasingly, as CPU, disk and readout speeds have allowed for more and more data to be recorded, experiments in nuclear and particle physics, for example, have tended to collect and record all data. Where possible, an approach known as Total Data Readout (Lazarus et al. 2001) has replaced the previous pre-selection or triggering processes, processes that reduced the volume of data to be recorded by the application of logical criteria to determine whether the data were relevant or not. Thus, a typical nuclear physics experiment might now generate hundreds of terabytes of data, recording everything that has been detected by the experimenter's system, and decisions about what to look for (and hence what is most relevant) are made later. Such an approach allows for the unexpected, for serendipitous discoveries of previously unanticipated processes and phenomena. While the sounds and smells associated with the experiment may not yet be recorded, the assumption that we know in advance what is relevant and interesting is increasingly itself becoming irrelevant in the light of our increased capacity to record everything. Similar to the light field camera, we may subsequently choose to refine, refocus or reorient ourselves, accessing new perspectives and finding new ways of interacting with the data long after the occurrence of the generating phenomenon.

Can our approach to learning evolve along similar lines? We seek ways of simultaneously interacting with multiple elements of the physical and digital environments, and of integrating those elements in new and creative ways. And it is here that AR may provide us with new tools and ways of seeing. When we augment reality, we add alternative perspectives: whether physically alternative, or those generated by 
the imaginations of others. The notion of the extended mind (Clark and Chalmers 1998) can itself be extended from its initial domain of memory and non-occurrent beliefs to extended perspectives and perceptions. AR offers simultaneous access to multiple perspectives, some of which have been externally generated, but which are incorporated by the viewer into a single, integrated perception of the object or phenomenon being observed. It thus has the power to generate collective memory, a shared story or meta-narrative. This capacity to connect individual stories, blending them into a shared network of experience, opens up new channels for generating mutual understanding and educational liberation.

\section{Connections with theories of learning}

Our conception of the way in which AR helps us to confront reality aligns with an essentially student-centred conception of learning. An AR is a flexible space, containing learning opportunities that the learner can grasp at will. Learning is liberated from traditional spaces such as classrooms, lecture theatres and labs and instead envelops the student wherever they are. Learning opportunities can be present at home, in the workplace, on public transport - and can be taken up or passed over. As more interactive applications of AR are developed, students can become critics and co-creators, leaving behind a record of their learning tied to the virtual artefact they have experienced. Our emphasis on accessing multiple perspectives resonates with two key pedagogical concepts - cognitive dissonance and variation theory.

First introduced by Festinger, Riecken and Schachter (1964), cognitive dissonance encapsulates the idea that people have a strong motivational drive to reduce the dissonance resulting from simultaneously holding conflicting cognitions by altering those existing cognitions or adding new ones to create consistency. The term is often linked to a constructivist theory of learning (Piaget 1950; Posner et al. 1982). The educational power of this idea comes when the learner's efforts to create consistency are directed in a way that leads to achieving a more correct or sophisticated understanding. A whole literature has developed concerning identification and correction of students' misconceptions (for example, Gilbert and Watts 1983; Pfundt and Duit 1994). Many of the interventions designed to address misconceptions make explicit use of cognitive dissonance - for example, it appears in Mazur's Peer Instruction technique (Mazur 1997), in which students are required to defend their answers to questions to their peers, before the correct answer is revealed and discussed. In a meta-analysis of such interventions, Guzzetti and co-authors found a common element of strategies that were effective in producing conceptual change was the use of procedures that produced conceptual conflict (Guzzetti et al. 1993).

Variation theory also provides an interesting framework from which to view the opportunities presented by AR. Connected with the qualitative research methodology of phenomenography, variation theory puts discerning differences between alternative understandings at the heart of learning.

In the presentation of variation theory, Mazur (1997) suggests that the most advanced form of learning leads to qualitatively changed ways of experiencing or conceiving of something. If, as they suggest, learning is a process by which we come to experience something differently, we must have become aware of or gained access to that variation. (Bowden, Bowden, and Marton 1998).

Suppose you were brought up in an environment (an alien planet) in which everything were brown. Under such circumstances, you would have no concept 


\section{Munnerley et al.}

brown, since brown is defined through its differences with other colours. Indeed you would have no concept of colour, only of tone or shade. When shown the existence of other colours - whether in person or in photographs - you experience an awareness of variation that you did not previously have. According to variation theory, it is this experience of variation that facilitates or even constitutes learning. In this way, variation theory suggests that teaching interventions, which allow students to discern variations and differences, promote effective learning. We attest that AR technologies offer a new and immensely flexible means to do this.

\section{How is AR being used?}

Outside education, perhaps the biggest focus for augmenting reality is augmenting locations. Information about places, what's around you, what used to be in the space, timetables for travel etc., are all now being built into the virtual spaces in real environments and accessed with a mobile device.

Augmented reality is unlike virtual reality, which seeks to create an alternative environment and so must attain a level of sophistication and immersion that requires specialist hardware and software, AR technologies seek to integrate the real and the virtual worlds together using mainstream devices. Allowing the virtual to co-habit or co-exist with the real reduces the need for complex hardware and software, so that reality augmentations rely on freely available web services that run on multiple platforms.

Augmented reality technologies have developed along two lines: geo-location and artefact-based. Geo-located AR works on the principle of defining a physical map reference or Point of Interest (POI) and then allowing the creator to add virtual assets (text, 3D and video) onto that POI. When a user, with the appropriate application installed on their mobile device, explores a space the POIs are revealed and the content can be accessed. POIs can be set anywhere in the world, by anyone, at any time regardless of their physical location.

Mobile web services are available for creating geo-location-based "layers" or "channels", meaning that it is becoming increasingly easy to create and distribute content. Geo-located content is growing quickly as the social web provides ever more ways of posting and locating personal media online.

Artefact-based AR works by tracking physical "markers" or "patterns" located on particular objects. A camera is used to track the marker, which the AR code then uses to display, for example, pre-built objects, animations and interactions. Markers can include barcodes and QR codes, however recent developments in image recognition and mobile technology allow for any image to be used as a marker as long as it is pre-defined in the AR code.

Augmented reality has been embraced in the world of advertising and marketing for its potential to make additional information available to customers. What started out as a simple marketing device has become a way for a company to project its brand image wherever its products are (for example, Smirnoff's recent use of artefact-based AR centres around limited edition bottles), or to provide additional information or guidelines about products (e.g. Lego's use of artefact-based AR to provide images of structures that can be made from their kits). This illustrates how technologies can provide new and potentially richer, multi-modal methods for remote communication.

Augmented reality is increasingly being used in architecture and design to envisage how a building or objects could look, or how it looked in the past. For example, an AR 
approach to the rebuilding of Christchurch after the devastating earthquakes in 2011 makes community engagement a central part of the design process. Researchers at the University of Canterbury have designed an AR application that allows the user to see both original and proposed replacements of damaged or demolished buildings in the city (Tadros 2011) thus allowing community input into the proposed locations of new buildings. When rebuilding historic buildings, digital models can be produced from archives, artefacts and expert knowledge, then placed at the site for assessment and critique by other experts and users, thus leading to improved models that pull together the knowledge of many to better reproduce the original, lost building.

One of the most striking developments in the use of AR has been its uptake in the visual arts, where its potential for playful subversion has been recognised and exploited. In a powerful demonstration of this potential, a group of artists used a geolocation-based approach to "hijack" New York's Museum of Modern Art (MoMA), inserting their own virtual exhibition throughout the museum's physical spaces and even creating an entire virtual seventh floor to the six storey building (Porter 2010). The exhibits were visible only to visitors with a mobile device, and included images of the Berlin Wall and a desert path suspended above the real-space sculpture garden.

Striking though this use of AR technologies is, its purpose was to communicate to an audience and to encourage them to consider the space around them (and the restrictions placed on the physical objects presented in that space). The communication was essentially one-way, hopefully prompting deep responses but not directly engaging the audience in shared criticism, debate or acts of co-creation.

We are thus now seeing elements of subversion, opportunism, transformation of spaces in the developing uses of AR. More importantly, we're seeing the creation of a virtual space within and completely integrated with real space, but (potentially) out of the control of the owners of the real space. This provides a strong contrast with "traditional" ideas of separate, real and virtual worlds, where virtual indicates a copy or simulation of the real world, rather than an expansion or enrichment of it. Augmentations are real things in themselves, a mixed reality (Milgram et al. 1995) of created and creative objects that enhance and enrich rather than copy or replace. Augmenting reality with the intention of integrating all spaces, increasing connectedness offers a glimpsed potential of what it might mean for us to become "realer than real" (Massumi 1987).

\section{Potential for AR in educational contexts: why we need to ensure uses are grounded in a philosophical/pedagogical framework}

Educational users of AR need to harness the potential for confronting, subverting and transforming realities and for creating shared narratives evident in the noneducational uses described above. AR offers several special pedagogical opportunities:

(1) Mobility

(2) Visualisation (which may be manipulated by the viewer)

(3) Alternative perspectives

(4) Comparison/contrast of multiple perspectives

(5) Integration of multiple perspectives

Current research into uses of AR in education has mainly focused on 1 and 2 - that is, the provision of flexible learning opportunities through delivery of information to 


\section{Munnerley et al.}

handheld devices, and the visualisation of information or perspectives that might otherwise not be available to students, either because of physical or financial constraints. It is now time to focus on $3-5$, but to do so with consideration of the overarching purpose, that is to create an increasingly student-centred learning experience in which the student connects, integrates, constructs and deconstructs his or her own meanings from his or her own experiences.

Some recent developments in higher education illustrate precisely why such an awareness/emphasis is essential if the potential of AR is not to be become just another passing fad. A good example comes from the increased focus on interactivity, particularly in traditionally content-focused disciplines such as the hard sciences. Without an understanding of the purpose of interactivity and curriculum design, efforts at increasing interactivity run the risk of being limited in their impact on student learning. Thus Mazur's Peer Instruction is reduced to multiple-choice clicker questions, with the game-show feel of the real-time audience response system replacing the intended provocation of cognitive dissonance through the confrontation of a student's prior understanding with an incompatible alternative. In one Australian university, iPads are handed out to first year science students as repositories for electronic texts, and in another to investigate the question of whether having an iPad in itself enhances student learning. Thus simulations are seen as enhancing student learning despite evidence that, at least in some cases, they have simply provided an animated visual that may be rote-learned instead of an equation.

Where individual teachers incorporate their uses of technology within a curriculum design approach informed by a belief in a particular theory of learning, great things may be achieved, but such development will inevitably be patchy, unpredictable and ad hoc. We call for a unified approach from the community as a whole. If developments are presented within a broader framework of how learning happens, they are much more likely to be exploited in ways that encourages deep learning. We need to focus on the learner; on what is happening when a more sophisticated understanding is developed, and what ingredients are required to help that happen.

Augmented reality technologies can be used to augment reality to promote reflection, integration, a questioning attitude, critical thinking and well-established learning goals in many traditional pedagogies. AR can provide additional depth and richness, or prompt learning characteristic of the more sophisticated outcomes such as those assessed by the SOLO taxonomy (Biggs and Collis 1982), which has been influential in guiding pedagogical practice for two decades. For example:

- Providing additional information on an object, such as relating to its origins the processes used to create it, or its impact on the environment: a mobile device could itself be labelled with information on the different elements and compounds used to make its components, together with their origins and histories.

- Providing access to physically inaccessible views of an object, whether closer or more distant, from above or below, or from any other perspective that has the potential to render the object unrecognisable or strange. Radical perspective changes could be used to challenge students' senses of familiar objects, and to encourage them to reflect on how their "usual" view may not be that shared by others. 
- Augmenting senses, such as object visualisation, possibly using infra-red or ultra-violet, or creating a journey through subsequent layers to the microscopic level. By providing new ways of seeing not available to unaugmented human senses, we can challenge students to reflect on the constraints on their own ways of seeing, and on how those constraints affect their interpretations of what they observe.

- Combining and comparing multiple views, simultaneously layering into a new dimension of change. By creating a third dimension spanning variation in parameters such as time, or visible frequencies, we hope to encourage awareness of similarities and differences.

- Confronting the alien or unexpected by exploring the reactions and responses, opinions and beliefs of others.

- Creating a shared narrative of learning or a pedagogical autobiography by explicit reflection on how being confronted with the memories, associations, beliefs and understandings of others transform the student's own individual understanding of a particular event, phenomenon or concept.

These variations can be accompanied by questions to prompt students' reflections, observations, and comments to evidence their own learning. Each variation focuses on higher-order thinking skills and learning outcomes such as integration, relationbuilding and creation. Each also offers opportunities for learners to confront their own beliefs, to juxtapose those beliefs with those of others and to create richer, more nuanced understandings in the process. These contributions can be combined to create a true learning commons, where the physical record of a space and the ideas generated within it are combined to create a multi-layered history of a multidimensional space. AR can thus provide opportunities for private contemplation or reflection, but also interaction, contestation and contribution: a multi-modal way to confront the full richness of reality.

\section{References}

Biggs, J. B. \& Collis, K. F. (1982) Evaluating the Quality of Learning: the SOLO Taxonomy (Structure of the Observed Learning Outcome), Academic Press, Watham, MA, USA.

Blum, T., et al. (2012) 'Mirracle: an augmented reality magic mirror system for anatomy education', Virtual Reality (VR) 2012 IEEE. IEEE Virtual Reality Conference 2012. IEEE, Costa Mesa, CA, pp. 115-116.

Bowden, J. A., Bowden, J. \& Marton, F. (1998) The University of Learning, Psychology Press, Hove, UK.

Clark, A. \& Chalmers, D. J. (1998). 'The extended mind'. ANALYSIS vol 58: no. 1, pp. 7-19.

Dünser, A., Grasset, R. \& Billinghurst, M. (2008) A survey of evaluation techniques used in augmented reality studies. In ACM SIGGRAPH ASIA 2008 courses, Association for Computing Machinery, NY, USA, p. 5.

El Sayed, N. A. M., Zayed, H. H. \& Sharawy, M. I. (2011) 'ARSC: augmented reality student card', Computer Education, vol. 56, pp. 1045-1061.

Festinger, L., Riecken, H. W. \& Schachter, S. (1964) When Prophecy Fails: A Social and Psychological Study of a Modern Group that Predicted the Destruction of the World, Harper \& Row, NY, USA.

Gilbert, J. \& Watts, D. (1983) 'Concepts, misconceptions and alternative conceptions: changing perspectives in science education', Studies in Science Education, vol. 10, pp. 61-98.

Guzzetti, B. J., et al. (1993) 'Promoting conceptual change in science: a comparative metaanalysis of instructional interventions from reading education and science education', Reading Research Quarterly, vol. 28, pp. 116. 
D. Munnerley et al.

Lazarus, I., et al. (2001) 'The GREAT triggerless total data readout method', IEEE Transactions on Nuclear Science, vol. 48, pp. 567-569.

Lee, K. (2012) 'Augmented reality in education and training', TechTrends, vol. 56, no. 2, pp. $13-21$.

Martin, S., et al. (2011) 'New technology trends in education: seven years of forecasts and convergence', Computer Education, vol. 57, pp. 1893-1906.

Massumi, B. (1987) Realer than real. Available at: www.anu.edu.au/hrc/first_and_last/works/ realer.htm

Mazur, E. (1997) Peer Instruction: A User's Manual, Prentice Hall, Old Tappan, NJ, USA.

Milgram, P., et al. (1995) Augmented Reality: A Class of Displays on the RealityVirtuality Continuum, Telemanipulator and Telepresence Technologies. SPIE, Bellingham, Washington, USA, pp. 282-292.

Pfundt, H. \& Duit, R. (1994) Bibliography, Students' Alternative Frameworks and Science Education [Bibliographie, alltagsvorstellungen und naturwissenschaftlicher Unterricht], Institute for Science Education, Kiel.

Piaget, J. (1950) The Psychology of Intelligence, Routledge, London, UK.

Porter, E. (2010) 'Is that a dagger I see on my iPhone?', The New York Times, 21 October 2012, p. 4.

Posner, G. J., et al. (1982) 'Accommodation of a scientific conception: toward a theory of conceptual change', Science Education, vol. 66, pp. 211-227.

Ross, S. M., Morrison, G. R. \& Lowther, D. L. (2010) 'Educational technology research past and present: balancing rigor and relevance to impact school learning', Contemporary Educational Technology, vol. 1, no. 1, pp. 17.

Tadros, E. (2011) 'Technology key to rebuilding Christchurch', The Sydney Morning Herald, 16 June 2011, p. 5. 